\title{
A Review of Influence of Various Types of Structural Bracing to the Structural Performance of Buildings
}

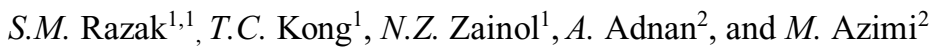 \\ ${ }^{1}$ Universiti Malaysia Perlis, Department of Civil Engineering Technology, 02100 Sungai Chuchoh, \\ Padang Besar, Perlis \\ ${ }^{2}$ Universiti Teknologi Malaysia, Faculty of Civil Engineering, Department of Structural and Material \\ Engineering, Universiti Teknologi Malaysia, 81310 UTM Skudai, Johor
}

\begin{abstract}
Excessive lateral drift can contribute significantly towards crack formation, leading to structural damage. The structural damage will in turn reduce the capacity of the structure and weaken it from the intended design capacity. Generally, lateral drift is more pronounced in higher and longer structure, such as high rise buildings and bridges. A typical method employed to control lateral drift is structural bracing, which works by increasing stiffness and stability of structure. This paper reviews the influence of various types of structural bracing to structural performance of buildings. The history of structural bracing is visited and the differences between numerous structural bracing in term of suitability to different types of buildings and loading, mechanisms, technical details, advantages and limitations, and the overall effect on the structural behaviour and performance are dissected. Proper and efficient structural bracing is pertinent for each high rise building as this will lead towards safer, sustainable and more economical buildings, which are cheaper to maintain throughout the life of the buildings in the future.
\end{abstract}

\section{Introduction}

Dynamic loads can impart significantly greater effect towards the structural response of a structure compared to the static loading. As such, the properties of the structure such as lateral stiffness and strength plays pivotal role towards achieving efficient structural performance against dynamic loads which include typhoons, earthquakes, blast and many others. The stiffness of the structure contributes greatly towards the P-delta effect of the structure. Dynamic loading especially those applied laterally such as the base shear due to earthquake ground motion are capable of exerting huge amount of energy on the structure. To avoid structural failure, some of the energy exerted by the dynamic load has to be properly dissipated so that the excessive lateral movement of the structure can be minimized. One of the most efficient methods for lateral movement resistance is structural bracing [1]. Structural bracings work by providing lateral stiffness and stability to the

${ }^{1}$ Corresponding author: skmuiz@,unimap.edu.my 
structure, especially for the multi-storey and high-rise buildings [2]. This subsequently increases the lateral resistance of the structure and reduces the internal forces through appropriate bracing arrangement. Thus, for economic reason, structural bracing has been widely used worldwide [1].

According to [2], there are three important criteria which govern the stiffness of structure. First, when the path of internal force is more direct, the structure becomes much stiffer. Second, the stiffness of structure increases when the distribution of the structure is uniform. Third, the stiffness of structure increase with the reduction in the internal forces. By incorporating bracings in accordance to these three criteria, a stiffer and more economical structure can be achieved.

\section{Early Development of Structural Bracing}

One of the earliest buildings to incorporate structural bracing is the Dewitt-Chestnut Building in 1965 in Chicago. The building used the frame tube system which is developed by Fazlur R. Khan. Later in 1970, Fazlur R. Khan developed the braced tube system for the John Hancock Centre, also in Chicago. The student of Khan which is Mikio Sasaki discovered and proposed the first design of diagonally braces tower in 1964 in the seminal thesis writing. In 1968, Robin Hodgkinson developed a brace which uses concrete in outward appearances for the purpose of alternate uses. The concept of exterior brace with concrete is applied on the Ontario Centre in Chicago in 1985. These ideas contribute signicantly to the design of high-rise structure design against the natural forces such as wind load, earthquake and gravity load [3].

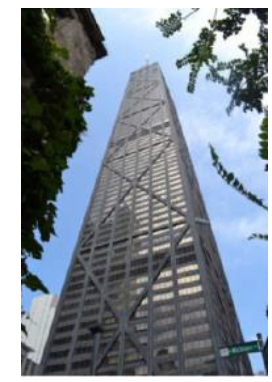

Fig. 1. John Hancock Centre.

The first eccentric braced frame design has been introduced to the building in Japan in 1970s [4]. In essence, the concept of Eccentric Braced Frame is derived from the Moment Resisting Frame and Concentrically Braced Frame. Consequently, this means that the advantages provided by both Moment Resisting Frame and Concentrically Braced Frame are integrated into a single structural system for structure which incorporate the use of Eccentric Braced Frame [5]. Chimeh et al [4] noted that there are many varieties in term of the placement of the link beam for the eccentric braced frame. Different placement or location of the link in the structure will lead to different structural response due to impact of lateral load.

\section{Concentrically Braced Frames (CBFs)}

Moment Resisting Frames (MRF) is traditionally assumed to contribute higher ductility to the structure compared to Concentrically Braced Frames (CBF). The inherent lack of ductility for the concentrically braced frames to be verified by introduced larger lateral strength in the previous seismic studies due to the fact that the specified value of the 
modification factor for CBF are much smaller compared to the MRF [6]. However, MRF is much more expensive than CBF since simple connection and smaller cross sectional area of beam and column is used in the concentrically braced frame. Besides that, the braces member in the structural frame are able to develop the axial forces and sustain the bending moment demand of the structure [7]. The understanding of the concentrically braced frame was been improved. During 80 s, there have a lots of the researcher starting their studies to investigate the features and important of the concentrically braced frame. This means that the realization on strength enhancement of simply structural design will lead to the brittle characteristic and undergoes a serious of damage to the structure under major of seismic event [6]. The example of concentrically braced frames is commonly classified into three major types which is Diagonally Braced Frames, V-Braced Frames and Chevron Braced Frame [8]. Concentrically Braced Frames is effectively in resisting the seismic excitation $[7,8]$. This means that they are resisting the lateral seismic acceleration primarily through the axial forces (tension and compression) and deformation of the braces, columns and beams [9].
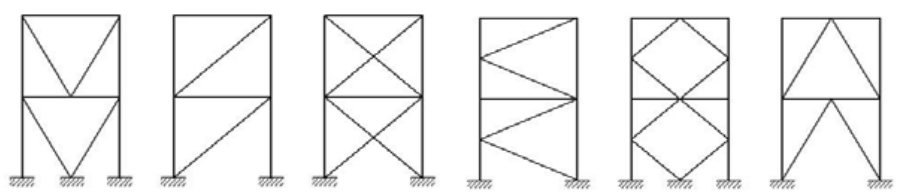

Fig. 2. Different Types of Concentrically Braced Frames.

Besides that, concentrically braced frame has been widely used in the structural frames since the braced frame is practical and cost effective $[2,10]$. CBF provide stability and lateral stiffness required by the modern seismic design provision [10]. Concentrically braced frame have a low plastic distribution capacity characteristic properties. This will tends to cause the development of the collapse configuration or called as plastic deformation in a few storeys [11]. Moreover, concentrically braced frames have a desired performance in the lateral stiffness due to the ductility limitation behaviour [12]. According to Eurocode 8 in the design of seismic behaviour of the concentrically braced frame, the elasticity behaviour of the column and beam should be maintained while the energy dissipating behaviour in the braces is required [11].

Assuming the tension is occur at the braces while the others is in compression under post buckling range behaviour, based on the principle, the equally distribution of the internal forces for the column and beam should be obtained. The design bending moment on the beams is due to the unbalances forces should be identified by apply firmly the design moment capacity. The factor that influence the seismic performance of the concentrically braced frame is affected by the slenderness and width-to-thickness ratio of the braces. Besides that, the braces connection is significant influenced by the secondary bracing deformation. Thus, this caused the gusset plate should be large and thick on the current provision. This enable to control the framing members by draw a huge stresses to the gusset plate welds. Unfortunately, the test that has been carried out indicated that gusset plate or at the welds before deformation capacity of the braces can be utilized which caused the fail in such bracing connection. Thus, this leads to recommend the thin and compact gusset plate and which able to improve the drift capacity [10].

\section{Diagonal Braced Frames (DBF)}

Single diagonal is consider effectively in resisting the lateral load [1]. A study by Maheri and Sahebi (1997) on the in-plane shear resistance among the three steel structural frame that are bare frame structure without brace, diagonally braced frame and double diagonal 
braced frame (X-bracing) showed that the resistance of diagonally braces and X-bracing are 2.4 and 4.0 times better respectively compared to bare structure [2].

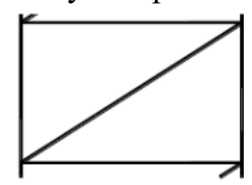

(a)

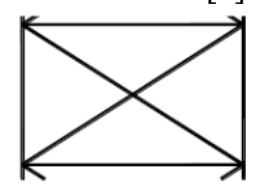

(b)

Fig. 3. Diagonal Bracing. (a) Single Diagonal Bracing (b) Double Diagonally Bracing [1]

When lateral load is applied to the braced frame, the diagonal braces are subjected to the compression while the horizontal web acts as the axial tension member in order to maintain the frame structure in equilibrium under lateral load [1]. In comparing the Xbracing and mega X-bracing, the mega X-bracing (diagrids) indicated that reduced in lateral drift with approximate $50 \%$ and $25 \%$ of material saving in terms of less steel bracing is used [2]. Besides that, diagrids structure provides higher torsion resistance which diagonal braces effective in minimizing shear deformation. In addition, diagrids structure possess higher structural flexibility than other bracing system. This means that diagrids structure is adjustable in the modules and angles(s) of diagonal into optimise structural performance [3].

The code of constraint in least weight optimisation is carried out by Kameshki and Saka (2001) through the genetic algorithms. This show that the weight for the X-bracing, chevron bracing and single diagonal bracing is arranged from the lowest to the highest. This indicated the X-bracing is higher efficiency in contributes the strength control compared to the optimized chevron bracing and single diagonal bracing are contribute to the stiffness control [2]. In term of the effects of brace configuration on the dynamic properties of frame, the $\mathrm{V}$-bracing and chevron bracing had the lowest natural frequency with approximately $75 \%$ from X-bracing. The X-bracing had highest natural frequency compared to V-bracing followed by the K-bracing.

On the other hands, a stiffness based design method for the preliminary estimation of the member sizes of steel braced tube structure is purposed by Moon (2010). In the studies, the empirical relationships between the numbers of duplicated modules, the tower aspect ratio and the optimum slope is between $40^{\circ}$ to $50^{\circ}$ of the X-brace were provided [2]. The slenderness ratio of the braces also influences the capacity of the energy absorption. This means that the smaller slenderness ratio of braces had a high capacity of energy absorption. In addition, the braces with small slenderness ratio decreasing the ductility behaviour but the deterioration of the energy dissipation became faster especially for the X-bracing [7].

The performances of the tension braces member in the design of single diagonal braces and X-bracing depends on the stiffness, resistance and ductility according to the European seismic design standard. This means that the early buckling of compression bracings and their low post buckling strength and stiffness are assumed. In the structural analysis, the compression in the diagonal is reasonably been neglected. The traditional issues in the seismic engineering community generated these code assumption on the improving of structural performance to the maximum state especially in the high seismic situation. However, if these assumption are applied to the low moderate seismicity condition, this could not been become economically feasible. Gioncu and Mazzolani (2014) indicated the most universal typology of lateral excitation resistant steel frame for concentrically braced frames and the compression diagonal in X-bracing is typically to be neglected among the weak points in the design [7].

\section{Chevron Braced Frames}


A high elastic stiffness and strength are the characteristics which in the chevron braces [13]. Chevron also effectively in the architectural functionality. This is important to allow the placement of the window and doorways at the braces bay [14]. However, the unbalanced force is created on the braces beam This is due to the fact that the braces with compression behaviour are deformed while the tension braces will remain to sustain the tension force during earthquake [15].

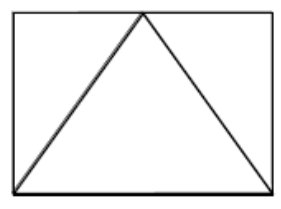

Fig. 4. Chevron Bracing [1]

The unbalanced distributed force is the major influences of the tension and compression braces which can cause the elastic deflection [10]. This causes the poor performances of the overall braces frame due to the deterioration on the braces [14]. This means that one of the braces resists the tension while the other braces are in compression at each storey of braces bay. Both of them distribute the lateral load equally in the elastic range before the buckling point. However, the tension braces remain in tension while the braces in compression lost all the axial load capacity after buckling. This contributes to the unbalanced distributed lateral load and caused large bending moment in the intersection of beam and braces [13]. This leads the mid span beam undergoes the plastic hinge and collapse due to unable to sustain the downward forces [10].

The AICS Seismic Provision have suggested that using a strong beam which is able to provide adequate strength such as deep and heavy beams to prevent the undesirable deterioration of frame $[13,15]$. This means that the strong beam mechanism is higher in the ductility and energy dissipation to delaying the braces fracture since the chevron is nonductile behaviour $[12,15]$. Besides that, the outstanding of the hysteretic response can be archived from the strong beam mechanism wherein a reasonable distribution of damage over the height of building can be contributed by the ductile braces [12]. Unfortunately, this unable to provide enough strength during lateral load and caused the soft story behaviour in the lower stories of the structure [15].

Struts are normally added between the story beam in other to replace the use of the deep and heavy beams, which are much more expensive. This arrangement is known as the zipper braces frame (ZBF). The struts mitigate the vertical load induced to the adjacent story braces and keep their axial load capacity after compression braces buckled [13]. Besides, the struts help to redistribute the loads on each storey. Besides that, the strut helps to redistribution the loads on each stories and contribute to the redistribution of deformation demands $[12,13]$. This caused to inelastic action along the height of frames and demand of uniform drift. Once the compression braces is buckling at the same time, it lead to the potentially damaging the structure or even possibility collapse is the defect of this configuration. This is because the plastic hinge occur at the beam since the unbalance force required to transfer to the columns by story beams [13]. A hat truss, also known as suspension system, is usually added at the top two stories to maintain the elastic behaviour when the braces and zipper column achieve the maximum capacity [13, 15]. This is means that the zipper column is against the vertical load from framing below since the hat truss acts as a tension member. 


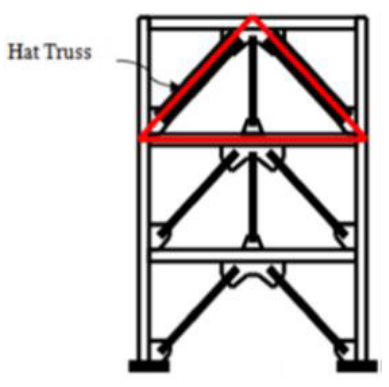

Fig. 5: Hat Truss in Zipper Braced Frames [13]

The elastic features of the top story braces should be maintain after the buckled of the braces below [15]. This is important to conquer the stability and the potential soft story formation problems. In the actual testing that done by previous researcher, it is found that the suspension zipper braces frame able to provide a higher strength and ductility features during seismic excitation ${ }^{[14]}$. There is more axial compression is developed by the suspended zipper braced frame for the upper stories compared to the chevron braced frame [13]. However, the increases of the required strength for zipper column is directly proportional to the height of the structure. It will caused architecture problems which unable the placement of window and doorway at the braces bay. This is because larger of the top story braces is used [15].

\section{Eccentrically Braced Frames}

Eccentrically braced frames are made of two short diagonal braces connecting the column to the middle span of beam with short segment of beam, to increase the lateral load resistance in terms of the seismic performance [16]. Besides that, the eccentric braces provides have architecture functionally which similarity with chevron braced frame $[1,5]$.
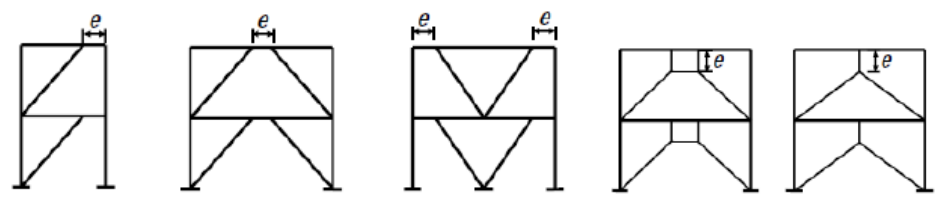

Fig. 6. Types of Eccentrically Braced Frames Depending on the Location of the Link Beam [4]

In the structural frame, the horizontal short segment in between the two braces member connection is called links [5]. The main function of the link beam is used to absorb the energy dissipation resulting from the lateral excitation $[4,12]$. This is because the links is used to control plastic deformation and maintain structural stability through dissipates the energy from the seismic excitation [5]. Moreover, the resistance of lateral movement in the eccentric braces is through the bending of the column and beam [1]. Therefore, the links provides the ductility behaviour to counter the impact seismic force from the lateral excitation $[17,18]$. 


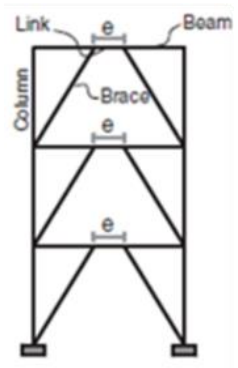

Fig. 7. Horizontal Links on the Eccentrically Braced Frames [5]

The strength, stability and ductility of the eccentric braced frame is influenced by the length of the horizontal links [5]. This is because the links indicated the capacity of energy dissipation inside the system [12]. Shorter horizontal length of links leads to higher shear yielding efficiency [5]. This is because the shear in the storey directly influences the shear in the links especially if the short links are used whereas bending may occur in the longer links [18]. Otherwise, the long links will contribute the flexural yielding compared to shorter links which only in shear yielding. If an intermediate length of the horizontal links to be used in the system, a combination of the shear and flexural yielding would be experienced. However, it has been shown that the short links has better performance in terms of rotation capacities compared to others. The previous researcher indicated that the short links have greater in strength and ductility when it subjected several cyclic load. Even through the longer links is able to provide the architecture freedom especially in the placement of the window and door opening [5].

Nevertheless, the lateral stiffness of eccentric braces is lower than the concentrically braced frames especially the diagonal bracing $[1,4]$. This is because the eccentric braces have a more ductile characteristic ${ }^{[4]}$. In addition, this is time consuming and expensive in the replacement of the horizontal links after it was damaged due to the seismic excitation [12]. However this causes the difficulties of the replacing or repairing the horizontal link beam since it is a primary component in the structure despite the high capacity of energy dissipation $[12,17]$. A vertical links is proposal to overcome the above disadvantages. This means that the vertical links is attached to the story beam. The vertical links is similarly with horizontal links which provide the ductility and acts as fuses which able to absorb energy. The vertical links able to deliver and withstand most of the shear force during the dynamic analysis. This means that accumulation of the shear at the links is not desired to be occur. Moreover, the links is deforming plastically. This is due to that links provide the uniform energy dissipation behaviour.

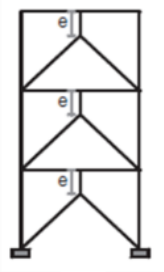

Fig. 8. Vertical Links on the Eccentrically Braced Frames [5]

Also, there is no rotational restraint at the lower end of the vertical links. It does not lead to significant damage to the story beam since the internal energy dissipation and intensive inelastic deformation are accumulated in the links. Hence, the replacement of the vertical links is effective and easier than horizontal links after lateral excitation [17].

Table 1. Comparison of the structural bracing 


\begin{tabular}{|c|c|c|}
\hline Diagonal Braced Frames & Chevron Braced Frames & Eccentrically Braced Frames \\
\hline \multicolumn{3}{|c|}{ Characteristic } \\
\hline $\begin{array}{l}>\text { High natural frequency } \\
>\text { Smaller slenderness } \\
>\text { High Capacity energy } \\
\text { absorption } \\
>\text { Decreasing the ductility } \\
>\text { Deterioration of energy } \\
\text { dissipation become faster } \\
\text { for X-bracing }\end{array}$ & $\begin{array}{l}>\text { Low natural frequency } \\
>\text { High elastic stiffness and } \\
\text { strength }\end{array}$ & $\begin{array}{l}>\text { Absorb energy dissipation } \\
>\text { Control plastic deformation } \\
>\text { Maintain structural stability } \\
>\text { Links provide ductility } \\
\text { behaviour } \\
>\text { Strength, stability and ductility } \\
\text { influenced by length of } \\
\text { horizontal links }\end{array}$ \\
\hline \multicolumn{3}{|c|}{ Mechanism } \\
\hline $\begin{array}{l}\text { Bracing acts as the } \\
\text { compression member while } \\
\text { the horizontal web member } \\
\text { (beam) acts as tension } \\
\text { member in the single } \\
\text { diagonal braced frame } \\
\text { Both bracing in the X- } \\
\text { bracing acts as the tension } \\
\text { and compression member } \\
\text { respectively }\end{array}$ & \begin{tabular}{|l}
$>$ Compression and tension \\
exert on each side of \\
braces respectively \\
$>$ Unbalances forces \\
created in braces beam \\
$>$ Compression braces are \\
deformed \\
$>$ Tension braces sustain \\
tension \\
$>$ Cause elastic deformation \\
$>$ Poor performance \\
$>$ Both braces distribute \\
lateral load equally \\
before buckling \\
$>$ Compression lost axial \\
load capacity after \\
buckling \\
$>$ Contribute unbalanced \\
distributed load capacity \\
after buckling \\
$>$ Large bending moment \\
on intersection of beam \\
and braces
\end{tabular} & $\begin{aligned} & \text { Resistance of lateral movement } \\
& \text { through bending of column and } \\
& \text { beam } \\
& \text { Shorter horizontal links lead to } \\
& \text { high shear yielding efficiency } \\
&>\text { Longer horizontal links } \\
& \text { contribute flexural yielding } \\
&>\text { Intermediate links will leading } \\
& \text { a combination of shear and } \\
& \text { flexural yielding experiences } \\
&>\text { Short links show better } \\
& \text { performances in terms of } \\
& \text { rotation capacities } \\
&>\text { Lateral stiffness lower than } \\
& \text { CBF especially diagonally } \\
& \text { bracing due to the eccentrically } \\
& \text { braces have more ductile } \\
&>\text { Time consuming and expensive } \\
& \text { in replacement horizontal links } \\
& \text { Difficulties of replacing or } \\
& \text { repairing since it is primary } \\
& \text { component of despite high } \\
& \text { capacity of energy dissipation }\end{aligned}$ \\
\hline \multicolumn{3}{|c|}{ Latest Improvement } \\
\hline $\begin{array}{l}\text { Mega X-Bracing (Diagrid) } \\
>\text { Reduced in lateral drift } \\
\text { with approximate } 50 \% \\
> \\
25 \% \text { of material saving in } \\
\text { term of less steel bracing is } \\
\text { used } \\
>\text { Minimizing shear } \\
\text { deformation } \\
>\text { Provide maximum } \\
\text { resistance against torsion } \\
>\text { Possess greater structural } \\
\text { flexibility than bracing } \\
\text { system } \\
>\text { Diagrid can be configured, } \\
\text { with some adjustment in } \\
\text { modules and angle(s) of } \\
\text { diagonals, to meet } \\
\text { architectural and structural } \\
\text { requirements. }\end{array}$ & $\begin{array}{l}\text { Strong beam } \\
>\text { Deep and heavy beam to } \\
\text { provide adequate strength } \\
\text { and prevent undesirable } \\
\text { deterioration of frame } \\
\text { Strut } \\
>\text { Replace deep beam and } \\
\text { heavy beam due to } \\
\text { expensive } \\
>\text { Mitigate vertical load } \\
\text { induced to adjacent story } \\
\text { braces and keep their } \\
\text { axial load capacity after } \\
\text { compression braces } \\
\text { buckled }\end{array}$ & $\begin{array}{l}\text { Vertical links } \\
>\text { No rotational restraint at lower } \\
\text { end } \\
>\text { Does not lead to significant } \\
\text { damage to beam since internal } \\
\text { energy dissipation and } \\
\text { intensive elastic deformation } \\
\text { accumulate in link } \\
>\text { Replacement more efficient and } \\
\text { easier }\end{array}$ \\
\hline
\end{tabular}

\section{Comparison}


Table below shows the comparison of the characteristic, mechanism and latest improvement among the structural bracing for diagonal braced frames, chevron braced frames and eccentrically braced frames. An effective structural bracing which able to reduce the structural performance due to lateral excitation by contribute to sustainable development. Eccentric braces able to reduce the structural repairing cost. This means that eccentric braces reduced the potential damage to the structure due to less maintenance activity toward the structure and reduce overall cost of the building. Meanwhile, safety of the occupant in the building is ensured because eccentric braces able to delay the structural response toward the earthquake by prolong the means time escape for the occupant escape from the building and contribute the comfort to the occupant at the same time. This is because the intensity that generated from the ground are reduced by dissipating the energy through the structural bracing. Thus, eccentric braces allow to prolong the half-life of structure.

\section{References}

1. Z. Siddiqi, R. Hameed and U. Akmal, Pak. J. Engg. \& Appl. Sci., 14, 17-26, (2014)

2. X. Yu, T. Ji and T. Zheng, Engineering Structures 89, 147-161, (2015)

3. K. Al-Kodmany and M. M. Ali, International Journal of High Rise Buildings 5, 271291, (2016)

4. M. N. Chimeh and P. Homami, 15th World Conferences on Earthquake Engineering (WCEE), Lisbon, (2012)

5. S. K. Azad and C. Topkaya, Journal of Constructional Steel Research 128, 53-73, (2017).

6. G. Brandonisio, M. Toreno, E. Grande, E. Mele and A. D. Luca, Journal of Construction Steel Research 78, 22-37, (2012).

7. A. Kanyilmaz, Journal of Construction Steel Research, 133, 1-18, (2017).

8. R. Sabelli, C. W. Roeder and J. F. Hajjar, Seismic Design of Steel Special Concentrically Braced Frame Systems: A Guide for Practicing Engineers (United States of America: U.S. Department of Commerce, 2013)

9. R. Sabelli, Research on Improving The Design and Analysis of Earthquake-Resistant Steel-Braced Frames (The 2000 NEHRP Professional Fellowship Report, 2001)

10. T. Okazaki, D. G. Lignos, T. Hikino and K. Kajiwara, Journal of Structural Engineer 139, 515-525, (2013)

11. M. Bosco, E. Marino and P. Rossi, 15th World Conference on Earthquake Engineering, Lisbon (2012)

12. D. M. Patil and K. K. Sangle, Structures 3, 282-305, (2015)

13. Y. Ozcelik, A. Saritas and P. M. Clayton, Journal of Construction Steel Research 119, 169-175, (2016)

14. M. D'Aniello, S. Costanzo and R. Landolfo, Journal of Constructional Steel Research 112, 305-324, (2015)

15. H. Yu, Y. Guo, Y. Zhang and X. Wang, Journal of Constructional Steel Research 120, $8-24,(2016)$

16. K. Torrie, Lateral Bracing Systems of Multi-Story Structures, (College of Engineering and Technology Brigham Young University, Provo, 1994)

17. M. G. Vetr, A. Ghamari and J. Bouwkamp, Journal of Building Engineering 10, 47-59, (2017)

18. X. M. Han, The 14th World Conference on Earthquake Engineering, Beijing, (2008). 